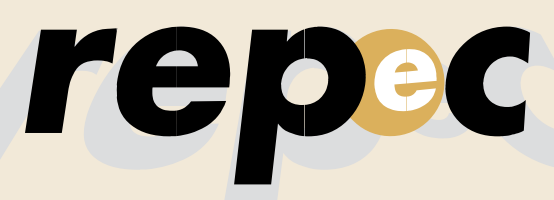

REPeC, Brasília, v. 13, n. 1, art. 5, p. 68-88, jan./mar. 2019 Disponivel online em www.repec.org.br D0l: http://dx.doi.org/10.17524/repec.v13i1.1999
Revista de Educação e Pesquisa em Contabilidade Journal of Education and Research in Accounting

Periódico Trimestral, digital e gratuito publicado pela Academia Brasileira de Ciências Contábeis

ISSN 1981-8610

\title{
Contabilidade e Arrendamento Mercantil/ Leasing: Revisão da Literatura Nacional e Internacional (2000-2018)
}

\author{
Resumo \\ Objetivo: Identificar e caracterizar a pesquisa sobre \\ arrendamento mercantil na área de contabilidade, no período de \\ 2000 a 2018. \\ Método: Três tipologias de revisão de literatura: descritiva; de \\ escopo e narrativa (Paré, Trudel, Jaana \& Kitsiou, 2015); em uma \\ amostra de 86 artigos (29 nacionais; 57 internacionais) sobre \\ arrendamento mercantil no período de 2000 a 2018/julho. \\ Resultados: A produção acompanhou a evolução do processo \\ de normatização internacional, com destaque a partir de 2006, \\ quando o tema entrou na agenda do IASB. Os grupos temáticos \\ identificados foram: (i) Decisões/Ações da Administração \\ (38\%); (ii) Avaliação de Riscos com base nas DFs (36\%); (iii) \\ Normatização do arrendamento (26\%). Mesmo com semelhança \\ temática, observa-se diferença nas abordagens metodológicas \\ utilizadas, com predominância de pesquisas analíticas no \\ cenário internacional e documentais no nacional. \\ Contribuições: Além da contribuição metodológica pelas três \\ tipologias de revisão, contribui-se: (i) com as revisões descritiva \\ e de escopo, ao sistematizar a apresentação dos estudos, \\ mostrando do que se trata a pesquisa sobre leasing, os temas, \\ métodos e técnicas, assim como indicações de lacunas; (ii) \\ com a revisão narrativa, ao se descrever as pesquisas de forma \\ a verificar se esses estudos têm demonstrado avanços sobre o \\ conhecimento. \\ Palavras-chave: Arrendamento Mercantil; Leasing; Revisão da \\ Literatura; Normatização; IASB/FASB.
}

Eduardo Bona Safe de Matos https://orcid.org/0000-0001-9548-7664 Doutorando em Controladoria e Contabilidade pela Universidade de São Paulo (USP) e Professor Assistente na Universidade de Brasília (UnB). Contato: Universitário Darcy Ribeiro - Prédio da Face, Sala BT2 54/7. Asa Norte. Brasília (DF). CEP: 70910-900.

E-mail: eduardobona@unb.br

\section{Fernando Dal-Ri Murcia}

https://orcid.org/0000-0002-2269-3667 Doutor em Contabilidade e Controladoria pela Universidade de São Paulo (USP) e Professor Doutor na Universidade de São Paulo (USP). Contato: Avenida Professor Luciano Gualberto, 908, FEA 3 - Sala 237. Cidade Universitária. São Paulo (SP). CEP: 5508-010.

E-mail: murcia@usp.br 


\section{Introdução}

A literatura sobre arrendamento mercantil permeia discussões em diferentes áreas, como Administração, Economia, Direito e Transportes (Matos, 2013). Representa, também, campo fortuito de pesquisa na contabilidade, principalmente em decorrência da necessidade de regulação do tema (Lipe, 2001; Matos \& Niyama, 2018; Spencer \& Webb, 2015).

O início da normatização contábil do leasing ocorreu nos Estados Unidos, na década de 1940, e desde então é constantemente atualizada. Já em 1998 as normas de leasing eram vistas como as de maior desgosto por parte dos usuários e preparadores de informações contábeis (Reither, 1998). Wolk, Dodd e Rozycki (2008) afirmam que essas normas contábeis, nos diferentes cenários nacionais e internacionais, são as que mais foram modificadas, além de o assunto estar entre os temas com mais emendas, interpretações e boletins técnicos emitidos pelos reguladores (Monson, 2001).

Como já pode ser observado, nos dois primeiros parágrafos, utilizam-se, no presente paper, as nomenclaturas "arrendamento mercantil" e "leasing" como sinônimas. Há críticas acerca da tradução para arrendamento mercantil ao alegar que esse contrato, no cenário nacional, se assemelha mais a uma forma de financiamento do que de manutenção operacional das entidades. Entretanto, essa é a tradução utilizada pelo CPC e pela legislação vigente, motivo pelo qual se opta pelo uso nas duas línguas de forma intercambiável. Além disso, com a ausência de separação dos tipos de contratos advinda com a IFRS 16, espera-se que essa diferença seja cada vez mais sutil.

Voltando aos aspectos contábeis de leasing, diversas são as críticas realizadas à contabilização do arrendamento, entre elas, a principal é a capacidade estruturação de operações decorrente da classificação do arrendamento em operacional ou financeiro, o que pode gerar informações off-balance ou reconhecidas no balanço das arrendatárias (Biondi, Bloomfield, Glover, Jamal, Ohlson, Penman \& Jeffrey, 2011). Tal questão impacta diferentes frentes, como a avaliação de riscos das empresas, a negociação de contratos de financiamento, a remuneração de executivos, etc.

Principalmente em decorrência de tais críticas, o assunto voltou a ser tratado pelos órgãos normatizadores internacionais, que emitiram estudos demonstrando a necessidade de atualização dos critérios contábeis do arrendamento de forma a atualizá-los às realidades do mercado (McGregor, 1996; Nailor \& Lennard, 2000). Esses estudos foram determinantes para a entrada do tema na agenda (inicialmente) conjunta do IASB e do FASB em 2006. Após a emissão de diversos documentos, os órgãos não entraram em completo acordo, demonstrando a dificuldade e a polêmica ainda atual sobre o tema, o que levou a emissão de normas diferentes por eles em 2016: IFRS 16 pelo IASB e Topic 842 pelo FASB. Apesar disso, em suma, as normas propõem o fim da classificação diferenciada para as arrendatárias, diminuindo as críticas da essência sobre a forma que derivavam de tal procedimento.

Ao mesmo tempo que houve diversas atualizações normativas também foram realizadas pesquisas científicas que tinham o leasing ou como tema/objeto de pesquisa, ou seja, o assunto não foi importante apenas para questões práticas e de regulação, mas também foi um tópico profícuo academicamente. Além dos estudos mais antigos e seminais que já questionavam e procuravam verificar os efeitos dos tratamentos contábeis do arrendamento (Ang \& Peterson, 1984; Beattie, Edwards \& Goodacre, 1998; Bowman, 1980; Ely, 1995; Imhoff \& Thomas, 1988; Imhoff Jr., Lipe \& Wright, 1991), em 2001, quando o tópico também já estava no radar de modificação normativa, a academia foi convocada a auxiliar com estudos que demonstrassem aspectos conceituais e empíricos que relacionavam a contabilidade e o arrendamento mercantil (Largay III, 2001).

Considerando a contínua relevância e contemporaneidade do tema para a área, objetiva-se, no presente estudo, identificar e caracterizar a pesquisa sobre arrendamento mercantil na área de Contabilidade no período de 2000 a 2018. Para tanto, procura-se sumarizar o conhecimento existente, por meio de revisões da literatura descritivas, de escopo e narrativas, nos moldes de Paré, Trudel, Jaana e Kitsiou (2015) (ver seção 2), discutindo as principais temáticas, metodologias, áreas de estudo, contribuições e caminhos futuros para pesquisa. Espera-se contribuir com a identificação de relações, sintonias, dissonâncias e as principais lacunas nessa literatura, tanto nacional quanto internacionalmente. 
Trabalhos internacionais de revisão de literatura sobre leasing já foram realizados na Contabilidade, porém todos de cunho narrativo e sobre pontos específicos do tema, como a decisão entre comprar versus arrendar (Morais, 2013), a contabilização do arrendamento operacional versus financeiro (Barone, Birt \& Moya, 2014; Lipe, 2001) e pesquisas sobre antecipações de mudanças contábeis (Spencer \& Webb, 2015).

Entre os diferenciais do presente estudo, portanto, está a união de três tipologias de revisão de literatura (descritiva, de escopo e narrativa) sobre um tema amplo e em um período recente, tomando como base uma métrica de seleção de artigos que seja ao mesmo tempo seletiva, representativa e compreensiva da população de pesquisas sobre arrendamento mercantil. Ainda, diferentemente das pesquisas citadas, no presente artigo não se faz o recorte de estudos que analisam apenas questões relacionadas às arrendatárias. Apesar de ainda serem escassos, são considerados também estudos que analisam as arrendadoras.

Podem ser discutidas diferentes contribuições de acordo com cada método de revisão de literatura empregado. Com as revisões descritiva e de escopo, contribui-se ao sistematizar a apresentação dos estudos, mostrando do que se trata a pesquisa sobre leasing, como são apresentados os principais temas, métodos e técnicas, assim como indicações de lacunas. Já na revisão narrativa, contribui-se ao se descreverem as pesquisas, de forma a verificar se esses estudos têm demonstrado verdadeiros avanços sobre o conhecimento já existente na área (Massaro, Dumay \& Guthrie, 2016).

Os resultados demonstraram uma concentração em três diferentes grupos temáticos de pesquisa: Normatização do Arrendamento; Avaliação de Riscos com base nas Demonstrações Financeiras (Classificação dos Arrendamentos); e Decisões/Ações da Administração. Esses grupos são desmembrados em dez subgrupos. Com base neles, realiza-se a revisão narrativa, mostrando, dentro de cada grupo, as principais contribuições e avanços já realizados e possíveis lacunas de pesquisa. Diferenças entre pesquisas nacionais e internacionais também são pontuadas e apresentadas, quando pertinente.

Em decorrência das diferentes revisões propostas, e considerando que os resultados da pesquisa são exatamente tais revisões, optou-se por uma estrutura diferenciada do paper. Após essa introdução, apresenta-se uma discussão dos procedimentos metodológicos, seguida pelas revisões de literatura descritiva e de escopo. Apenas após a identificação das principais propostas temáticas é que é apresentada a revisão narrativa: seção em que serão discutidas as propostas temáticas identificadas. Por fim, são apresentadas as considerações finais do trabalho.

\section{Procedimentos Metodológicos}

Para atingir o objetivo de pesquisa e contribuir com a discussão acerca do tema Arrendamento Mercantil, utiliza-se como premissa metodológica, para a caracterização do presente estudo, o modelo de tipologias de revisões de literatura desenvolvido por Paré et al. (2015). Mesmo Paré et al. (2015) sendo um paper oriundo da ciência da informação, os autores desenvolvem um quadro teórico-conceitual aplicável às mais diversas áreas. Assim, optou-se, no presente artigo, pela união de três revisões de literatura, já que todas elas partem do objetivo comum de sumarização do conhecimento existente sobre determinado tema, utilizando como base tanto literaturas de natureza conceitual como empíricas.

Com base no estudo citado, as revisões realizadas são: descritiva, de escopo e narrativa. Tem-se como características semelhantes de tais tipologias a natureza de investigação, que tende a ser de questões amplas, sem delineamento específico de discussão, e a ausência de intenção, nessas revisões, de avaliação da qualidade da literatura discutida (Paré et al., 2015). 
Espelhando-se nas características individuais de cada tipologia, as duas primeiras revisões (descritiva e de escopo) necessitam de uma apresentação explícita de como foi feita a seleção dos papers, ou seja, exigem certa padronização, de forma a se obter uma amostra representativa e compreensiva da população. Ambas são caracterizadas por métodos de análise e síntese dos resultados baseados em análises de conteúdo, de frequências e de temáticas (Paré et al., 2015). No Brasil, revisões semelhantes já foram realizadas sobre valor justo (Matos, Araújo, Guerra \& Murcia, 2017) e disclosure social e ambiental (Nascimento, Santos, Salotti \& Murcia, 2009). A revisão narrativa, como o próprio nome diz, é apresentada por meio de um resumo narrativo das pesquisas existentes e procura ter certa seletividade na análise dos artigos, ou seja, não busca analisar todas as pesquisas, mas, sim, aquelas consideradas mais relevantes para a descrição do estado da arte de determinado tema (Paré et al., 2015).

De forma específica, a revisão de literatura descritiva leva em consideração a magnitude do conhecimento em determinada área ou tema de pesquisa, mostrando, principalmente por meio de estudos empíricos, os principais achados, metodologias e origens teóricas (Paré et al., 2015). Já a revisão de escopo, apesar de muito similar à revisão descritiva, procura demonstrar a natureza e extensão das produções em determinado tema, de forma a identificar os possíveis gaps na literatura e que não estão englobados ainda no estado da arte (Paré et al., 2015). Por fim, a revisão narrativa possui uma natureza mais seletiva, objetivando discutir de forma dialógica as principais pesquisas e os achados, tendo, portanto, o objetivo de trazer à tona o estado da arte daquele tema (Paré et al., 2015).

Considerando a necessidade de seleção de uma amostra compreensiva e representativa para a revisão descritiva e de escopo, procurou-se manter um padrão de seleção com validade interna e replicabilidade (Smith, 2003). Assim, foram selecionados artigos sobre leasing de origem nacional e internacional no período de 2000 a julho de 2018.

Para a seleção dos artigos internacionais, utilizou-se como base o estudo de Matherly e Shortridge (2009), que classificam os 30 principais periódicos internacionais de contabilidade. Após isso, foram selecionados os papers que possuíam, no título, nas palavras-chave ou resumo, alguma palavra que remetesse ao tema de arrendamento mercantil, como: lease(s), leasing(s), lessee(s), lessor(s), arrendamento, IAS 17, IFRS 16, SFAS 13 e CPC 06. Para a seleção dos nacionais, utilizou-se a mesma lógica de filtro de seleção (tanto com as palavras em inglês quanto em português), sendo ele aplicado aos periódicos indexados na base Spell.

Qualquer método de seleção de amostra possui limitações e não é diferente no presente paper. Apresenta-se como principal limitação o fato de utilizar-se um ranking específico de classificação de journals da área (Matherly \& Shortridge, 2009), deixando fora da amostra outros periódicos que também são relevantes para a Contabilidade. Entretanto, entende-se que a utilização deste critério garante tanto validade interna como externa na pesquisa, uma vez que, mesmo que fossem incluídos mais journals, haveria diferenças significativas no estado da arte da pesquisa sobre leasing, uma vez que a amostra é composta dos principais periódicos da área. Ainda, com esse critério, são cumpridas as exigências para a seleção dos papers para as revisões de literatura realizadas nos moldes de Paré et al. (2015), que exigem uma seleção compreensiva e representativa da população, porém não exaustiva.

Após análises iniciais de aderência temática, foram selecionados 86 artigos científicos, sendo 57 internacionais e 29 nacionais. Como forma de validação das palavras-chave da pesquisa, realizou-se uma nuvem de palavras com base em todos os títulos selecionados, conforme Figura 1. Um dos objetivos foi verificar se outras palavras poderiam ter sido consideradas na seleção inicial. Além disso, a aparição de determinados termos já adianta indícios de possíveis categorias de classificação temática. 


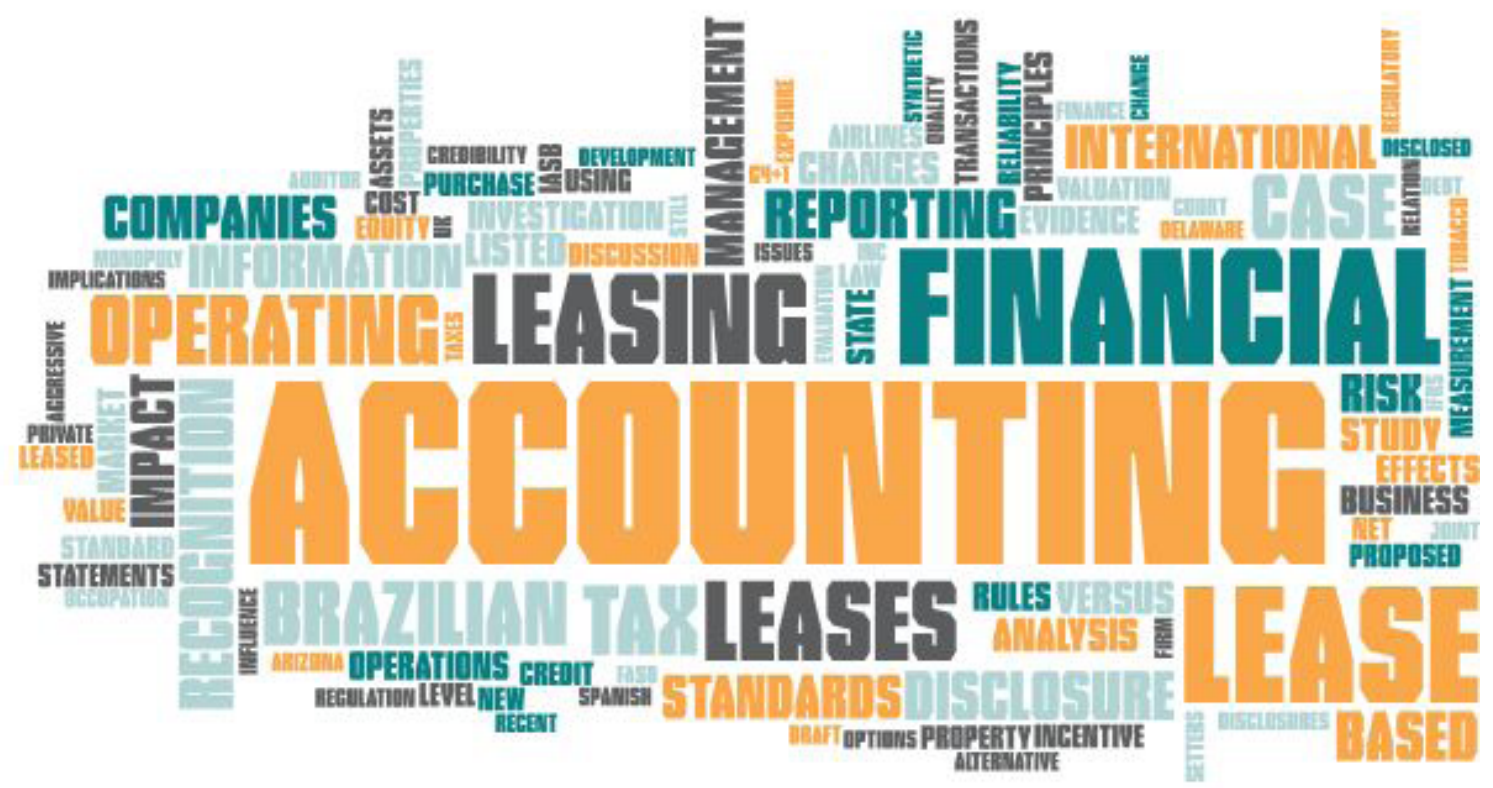

Figura 1. Nuvem de palavras da amostra selecionada

Fonte: elaboração própria

Verifica-se que as palavras que mais apareceram ou (i) referem-se a aspectos gerais da contabilidade (como financial, accounting, operating,...) ou (ii) a palavras específicas já utilizadas na seleção dos artigos. De certa forma, isso demonstra que o método de seleção dos artigos conseguiu capturar as principais produções científicas sobre o tema.

Ainda sobre a amostra, optou-se pelos artigos publicados no período de 2000 a 2018 (até julho). Esse período deve-se, principalmente, ao afloramento das discussões sobre o tema, motivados pelas pesquisas iniciais, conduzidas pelo grupo de normatizadores "G4+1" (grupo de normatizadores da Austrália, Canadá, Nova Zelândia, Reino Unido e Estados Unidos, mais o Iasc, atual IASB, como convidado) para uma possível mudança na normatização internacional. Além disso, a literatura anterior já é discutida no estudo de Lipe (2001), sendo que esse estudo, inclusive, serviu como base teórica para a classificação temática das pesquisas recentes.

Para a análise dos artigos, foi realizada uma classificação em grupos e subgrupos temáticos, conforme Figura 2, sendo possível a quantificação dos artigos por similaridade de objetivos (cumprindo requisitos das revisões de literatura descritiva e de escopo), o que possibilita uma sintetização por similaridade dos papers (revisão narrativa).

\begin{tabular}{|c|c|}
\hline Grupo & Subgrupo \\
\hline \multirow{4}{*}{ Normatização do Arrendamento } & Efeitos/Impactos e(ou) Descrição/Críticas de mudanças normativas \\
\hline & Análise do processo normativo \\
\hline & Comparação de normas \\
\hline & Regras versus princípios \\
\hline \multirow{3}{*}{$\begin{array}{l}\text { Avaliação de Riscos com base nas DFs } \\
\text { (Classificação dos Arrendamentos) }\end{array}$} & Usuários, riscos e efeitos do (não) reconhecimento do leasing \\
\hline & Qualidade de disclosure/auditoria \\
\hline & Indicadores contábeis e/ou covenants \\
\hline \multirow{3}{*}{ Decisões/Ações da Administração } & Efeitos tributários \\
\hline & Gerenciamento de resultados/informações \\
\hline & Determinantes. Decisão entre arrendamento ou compra/venda. \\
\hline
\end{tabular}

Figura 2. Grupos e Subgrupos temáticos de classificação

Fonte: elaboração própria 
A criação e consequente classificação dos grupos/subgrupos temáticos foi feita tomando-se como base e respaldo teórico revisões de literatura narrativas anteriores (Barone et al., 2014; Lipe, 2001; Morais, 2013; Spencer \& Webb, 2015). Cabe ressaltar que cada artigo foi classificado em apenas um subgrupo temático. Em muitos casos os artigos poderiam, eventualmente, ser classificados em mais de um subgrupo, porém para comparabilidade, optou-se pela classificação única, tendo como base sempre o objetivo principal da pesquisa analisada.

Ainda, foram realizadas classificações com base nos métodos utilizados nas pesquisas, áreas de concentração, foco da análise (arrendador ou arrendatário) e tipos de produção. Para esse detalhamento, opta-se pela explicação, tanto dos grupos/subgrupos temáticos quanto dos demais pontos analisados, nas seções de revisão das literaturas propriamente ditas como uma forma de simplificação e sistematização da leitura. Assim, à medida que os resultados são discutidos, também são apresentadas as métricas que levaram a tais análises e classificações. Esta seção, portanto, serve mais como balizador do trabalho realizado e suas justificativas teóricas.

\section{Revisão Descritiva e de Escopo da Literatura}

Pretende-se iniciar a discussão com as características gerais da produção, como principais journals, anos de produção, autores, áreas e métodos. Ao final, serão descritos os grupos/subgrupos temáticos, que darão subsídio para a revisão de literatura narrativa.

Apresenta-se, inicialmente, a evolução da quantidade dos estudos publicados no período, segregados, conforme Figura 3, entre produções nacionais e internacionais.

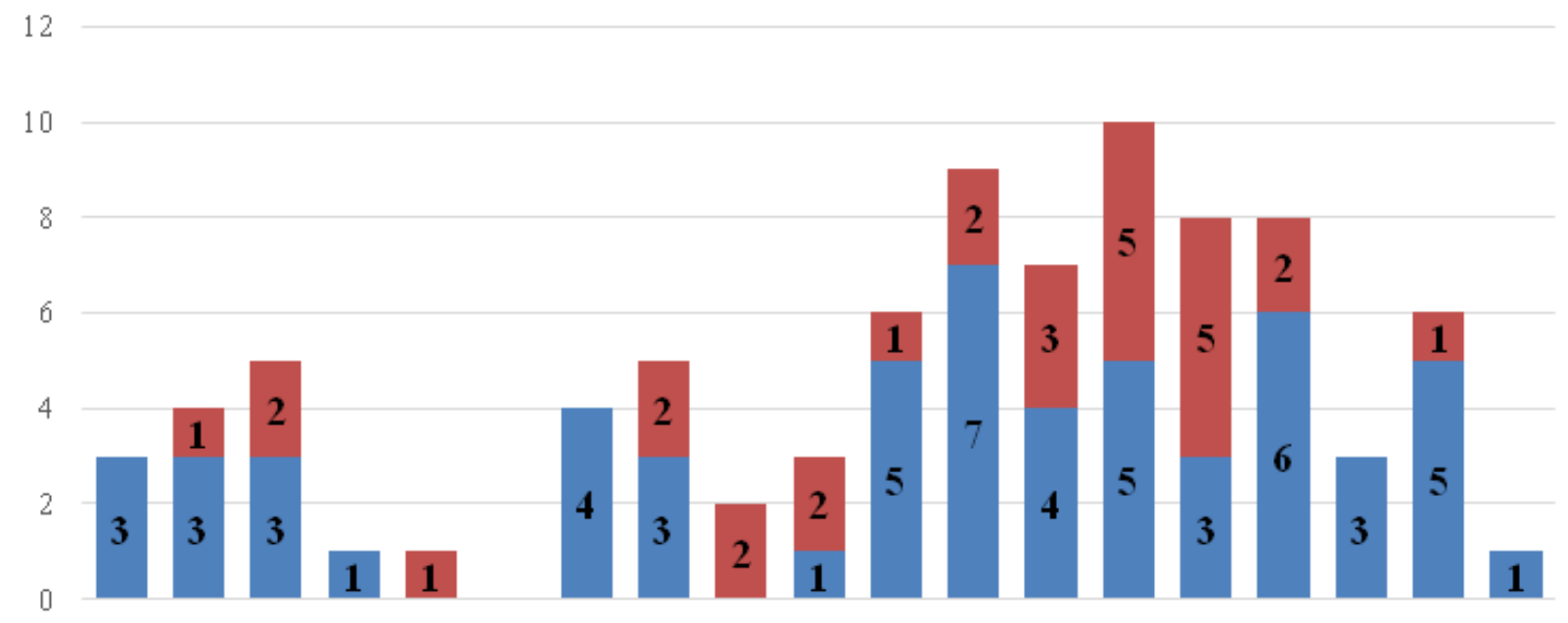

2000200120022003200420052006200720082009201020112012201320142015201620172018

\section{- Internacional $\square$ Nacional}

Figura 3. Quantidade de artigos nacionais e internacionais publicados por ano Fonte: elaboração própria

Há diferentes reflexos da quantidade de artigos publicados que podem ser justificados com base na evolução do processo normativo de leasing conduzido pelo FASB e IASB.

O primeir o movimento ocorre de 2000 a 2002, principalmente internacionalmente. Esse período foi logo após a emissão de um dos estudos feitos pelo G4+1. Esse grupo emitiu dois estudos sobre leasing: o primeiro sobre pontos conceituais que poderiam ser alvo de críticas na normatização até então vigente (McGregor, 1996); e o segundo estudo sobre as propostas práticas de mudanças, com lançamentos contábeis e impactos nas demonstrações financeiras (Nailor \& Lennard, 2000). Após esses estudos, a Accounting Horizons lançou uma chamada para artigos que analisassem essas propostas, sendo mais um chamariz para o aumento de pesquisas. 
O segundo movimento, tanto nacional quanto internacional, ocorre a partir de 2006, com crescimento mais acentuado após 2010. Observa-se que o processo normativo internacional sobre arrendamento entrou na agenda em 2006, com emissão de discussion paper em 2009, exposure drafts em 2010 e 2013 e normas finais em 2016. Assim, foi um momento de afloração do debate, com propostas normativas diferentes entre si e que foram utilizadas como bases para estudos. Espera-se, agora, que haja um terceiro momento de aumento dos estudos após 2019 - ano de início da vigência da IFRS 16 - pois já haverá dados empíricos reais para análise dos seus efetivos impactos.

Portanto, infere-se que a discussão por parte dos normatizadores eleva a relevância científica do tema, o que é naturalmente espelhado pela produção acadêmica, ou seja, a produção científica sobre o tema pode ter sido reflexo das discussões sobre regulação, o que faria com que a pesquisa se comportasse como um balizador sobre os efeitos das decisões normativas. Do mesmo modo, o estudo acadêmico também serve de input para os órgãos reguladores. De fato, esse acaba sendo um dos objetivos da pesquisa na área de Contabilidade Financeira, qual seja, o de trazer uma visão científica e crítica acerca do tema, contribuindo para o processo normativo contábil.

Assim como a tempestividade da produção, cabe a análise dos principais periódicos com publicações nesse período, conforme pode ser observado na Tabela 1.

Tabela 1

Principais periódicos científicos, nacionais e internacionais, com produção sobre leasing

\begin{tabular}{|c|c|c|c|c|c|c|c|c|c|}
\hline Periódicos & $\begin{array}{l}\text { Cont } \\
\text { Fin }\end{array}$ & Trib & $\begin{array}{l}\text { Eco / } \\
\text { Adm }\end{array}$ & Reg & Aud & Ger & Hist & Total & $\begin{array}{c}\% \\
\text { Vertical }\end{array}$ \\
\hline \multicolumn{10}{|l|}{ Painel A - Internacionais } \\
\hline AccountingHorizons & 10 & - & 1 & 1 & 1 & - & - & 13 & $23 \%$ \\
\hline JournalofStateTaxation & - & 10 & - & - & - & - & - & 10 & $18 \%$ \\
\hline The Accounting Review & 4 & - & - & - & 1 & 1 & - & 6 & $11 \%$ \\
\hline Issues in AccountingEducation & 3 & 1 & - & - & 1 & - & - & 5 & $9 \%$ \\
\hline Journal of Business Finance \& Accounting & 4 & - & - & - & - & - & - & 4 & $7 \%$ \\
\hline EuropeanAccounting Review & - & - & - & - & 1 & - & 1 & 2 & $4 \%$ \\
\hline Journal of Accounting and Public Policy & 1 & 1 & - & - & - & - & - & 2 & $4 \%$ \\
\hline JournalofAccountingResearch & 1 & - & - & - & 1 & - & - & 2 & $4 \%$ \\
\hline Research in AccountingRegulation & 1 & - & - & 1 & - & - & - & 2 & $4 \%$ \\
\hline Outros com 1 publicação cada & 7 & - & - & 1 & - & 1 & 2 & 11 & $19 \%$ \\
\hline Total Internacional & 31 & 12 & 1 & 3 & 5 & 2 & 3 & 57 & $100 \%$ \\
\hline \% Horizontal (Internacional) & $54 \%$ & $21 \%$ & $2 \%$ & $5 \%$ & $9 \%$ & $4 \%$ & $5 \%$ & $100 \%$ & \\
\hline \multicolumn{10}{|l|}{ Painel B - Nacionais } \\
\hline Enfoque: Reflexão Contábil & 3 & - & - & 1 & - & - & - & 4 & $14 \%$ \\
\hline $\begin{array}{l}\text { Revista de Contabilidade do Mestrado em } \\
\text { Ciências Contábeis da UERJ }\end{array}$ & 2 & 1 & - & - & - & - & - & 3 & $10 \%$ \\
\hline Organizações Rurais \& Agroindustriais & - & - & 2 & - & - & - & - & 2 & $7 \%$ \\
\hline Pensar Contábil & 2 & - & - & - & - & - & - & 2 & $7 \%$ \\
\hline Revista Contabilidade Vista \& Revista & 1 & - & - & 1 & - & - & - & 2 & $7 \%$ \\
\hline Revista de Finanças Aplicadas & 2 & - & - & - & - & - & - & 2 & $7 \%$ \\
\hline Outros com 1 publicação cada & 7 & - & 4 & 2 & - & 1 & - & 14 & $48 \%$ \\
\hline Total Nacional & 17 & 1 & 6 & 4 & 0 & 1 & 0 & 29 & $100 \%$ \\
\hline$\%$ Horizontal (Nacional) & $59 \%$ & $3 \%$ & $21 \%$ & $14 \%$ & $0 \%$ & $3 \%$ & $0 \%$ & $100 \%$ & \\
\hline \multicolumn{10}{|l|}{ Painel C - Total Internacionais e Nacionais } \\
\hline Total Geral & 48 & 13 & 7 & 7 & 5 & 3 & 3 & 86 & \\
\hline \% Horizontal (Geral) & $56 \%$ & $15 \%$ & $8 \%$ & $8 \%$ & $6 \%$ & $3 \%$ & $3 \%$ & $100 \%$ & \\
\hline
\end{tabular}

Legenda: ContFin (Contabilidade Financeira/Teoria da Contabilidade); Trib (Tributária); Eco/Adm (Economia/ Administração); Reg (Regulação); Aud (Auditoria); Ger (Gerencial); Hist (História).

Fonte: elaboração própria 
Dos 30 journals internacionais da amostra, 20 tiveram alguma publicação selecionada, assim como os periódicos nacionais. Aqui se pode verificar uma diferença no comportamento das produções por nacionalidade, algo que já é mais explicado pela forma como a publicação científica funciona nos cenários analisados. Os periódicos internacionais apresentam escopos de publicações mais claramente definidos, que demonstram seus principais interesses. Pode-se ver, por exemplo, a predominância da Accounting Horizons e da The Accounting Review nas publicações de leasing com viés para contabilidade financeira e com uso de técnicas quantitativas, enquanto o Journal of State Taxation, que é um periódico mais técnico, com publicações voltadas para questões tributárias. A análise de pontos tributários, mais uma vez, reforça a relevância do tema para a área, uma vez que a figura do arrendamento, em muitos casos, ainda é utilizada devido a diferentes vantagens tributárias que essa operação pode trazer.

Nacionalmente não é possível afirmar a existência de concentração, sendo as produções ainda miscigenadas entre os journals, com pequeno destaque para a "Enfoque: Reflexão Contábil", mas, não, algo que a torne uma referência sobre o assunto. Isso pode ser explicado pela ausência de direcionamento das publicações nesse cenário, algo que pode vir a acontecer, assim como no internacional, com o aumento da qualidade e o desenvolvimento da produção científica.

Ainda nessa lógica, a Issues in Accounting Education, que possui um escopo mais voltado para questões de ensino, apresentou cinco publicações no período analisado ( $9 \%$ da amostra internacional). A publicação nesse veículo demonstra a relevância do tema, em razão das críticas, da polêmica, e das dificuldades de reconhecimento, entre outros fatores, sendo possível afirmar que o assunto é interessante para a discussão em sala de aula, fato este que pode ser triangulado com a existência de casos de ensino e revisões de literatura específicas sobre o assunto, como pode ser observado na Tabela 2.

Tabela 2

Relação dos métodos de investigação, abordagem “quantitativa x qualitativa” e origem da produção.

\begin{tabular}{lccccccccc}
\hline \multirow{2}{*}{ Método } & \multicolumn{3}{c}{ Internacional } & \multicolumn{3}{c}{ Nacional } & \multicolumn{3}{c}{ Total } \\
\cline { 2 - 12 } & Quali & Quant & Total & Quali & Quant & Total & Quali & Quant & Total \\
\hline Caso de ensino & 4 & - & $\mathbf{4}$ & - & - & - & 4 & - & $\mathbf{4}$ \\
\hline Experimento & - & 8 & $\mathbf{8}$ & - & - & - & - & 8 & $\mathbf{8}$ \\
\hline Framework & 1 & 1 & $\mathbf{2}$ & 1 & - & $\mathbf{1}$ & 2 & 1 & $\mathbf{3}$ \\
\hline Modelagem & 1 & - & $\mathbf{1}$ & - & 1 & $\mathbf{1}$ & 1 & 1 & $\mathbf{2}$ \\
\hline Pesquisa Analítica & - & 17 & $\mathbf{1 7}$ & - & $\mathbf{7}$ & $\mathbf{7}$ & - & 24 & $\mathbf{2 4}$ \\
\hline Pesquisa de Campo/Estudo de caso & 4 & - & $\mathbf{4}$ & - & - & - & 4 & - & $\mathbf{4}$ \\
\hline Pesquisa documental/levantamento & 1 & - & $\mathbf{1}$ & 14 & - & $\mathbf{1 4}$ & 15 & - & $\mathbf{1}$ \\
\hline Survey & 1 & - & $\mathbf{1}$ & 2 & - & $\mathbf{2}$ & 3 & - & $\mathbf{3}$ \\
\hline Técnico & 10 & - & $\mathbf{1 0}$ & - & - & - & 10 & - & $\mathbf{1 0}$ \\
\hline Teórico/Revisão & 9 & - & $\mathbf{9}$ & 4 & - & $\mathbf{4}$ & 13 & - & $\mathbf{1 3}$ \\
\hline Total Geral & $\mathbf{3 1}$ & $\mathbf{2 6}$ & $\mathbf{5 7}$ & $\mathbf{2 1}$ & $\mathbf{8}$ & $\mathbf{2 9}$ & $\mathbf{5 2}$ & $\mathbf{3 4}$ & $\mathbf{8 6}$ \\
\hline
\end{tabular}

Fonte: elaboração própria

Para a definição das abordagens metodológicas, utilizou-se como base os estudos de Nascimento et al. (2009) e Smith (2003).Algumas pesquisas poderiam ser classificadas como multi-métodos, porém, com o objetivo de manter uma consistência de classificação, optou-se pela classificação baseada na principal ferramenta utilizada para a resolução do objetivo principal de pesquisa relacionado ao leasing, assim como a classificação na abordagem "qualitativa versus quantitativa". O mesmo critério foi utilizado para a classificação temática das pesquisas. 
Observa-se, em conjunto com o discutido anteriormente, a presença de 4 casos de ensino, todos publicados na Issues of Accounting Education. Ao contrário do mainstream atual, há uma presença de maior número de pesquisas qualitativas, em ambos os cenários. Internacionalmente, esse fato pode ser explicado pelas 10 publicações de natureza técnica publicadas, que possuem como gatilho análises de propostas tributárias. Retiradas essas publicações, ao menos no cenário internacional, há uma maioria de estudos quantitativos.

Outro ponto a ser destacado é a maior diversidade de métodos nas pesquisas internacionais. Enquanto todos os métodos elencados possuem ao menos uma aplicação no cenário internacional, a pesquisa nacional apresenta sua concentração em seis métodos, com supremacia da pesquisa documental qualitativa. Métodos como estudo de caso, experimentos e casos de ensino não foram utilizados nas pesquisas nacionais, o que, obviamente, não decorre da impossibilidade de aplicação.

Observa-se, também, a relevância dos estudos teóricos, tanto nacionalmente como internacionalmente, o que demonstra que o tema ainda não é um consenso na academia, fazendo com que pesquisas argumentativas e teóricas tenham espaço de publicação ao demonstrar críticas e propostas, principalmente no que concerne a normatização do assunto.

Estritamente com relação aos métodos, há diferenças, como já vistas, entre as aplicações nos cenários nacional e internacional. Enquanto as pesquisas analíticas, que são aquelas em que se usam modelos quantitativos para a exploração do problema de pesquisa, são maioria nas pesquisas internacionais, pesquisas documentais são as mais presentes no cenário nacional. Isso fica nitidamente evidenciado na Tabela 3.Embora as informações dos painéis dessa tabela sejam semelhantes, no primeiro são contrastados os grupos temáticos com a origem do estudo e no segundo os grupos com o enfoque de aplicação.

Tabela 3

\section{Grupos e Subgrupos temáticos por origem da publicação e por objeto de pesquisa analisado}

\begin{tabular}{|c|c|c|c|c|c|c|}
\hline \multicolumn{7}{|c|}{ Painel A - Grupos temáticos por origem da produção } \\
\hline Grupos/Subgrupos & Int & $\%$ & $\mathrm{Nac}$ & $\%$ & Total & $\%$ \\
\hline $\begin{array}{l}\text { Efeitos/Impactos e(ou) Descrição/Críticas de } \\
\text { mudanças normativas }\end{array}$ & 6 & $0 \%$ & 3 & $10 \%$ & 9 & $10 \%$ \\
\hline Análise do processo normativo & 2 & $4 \%$ & 3 & $10 \%$ & 5 & $6 \%$ \\
\hline Comparação de normas & - & $0 \%$ & 2 & $7 \%$ & 2 & $2 \%$ \\
\hline Regras versus princípios & 5 & $9 \%$ & 1 & $3 \%$ & 6 & $7 \%$ \\
\hline Normatização do Arrendamento & 13 & $23 \%$ & 9 & $31 \%$ & 22 & $26 \%$ \\
\hline $\begin{array}{l}\text { Usuários, risco e efeitos do (não) } \\
\text { reconhecimento do leasing }\end{array}$ & 13 & $23 \%$ & 1 & $3 \%$ & 14 & $16 \%$ \\
\hline Qualidade de disclosure/auditoria & 5 & $9 \%$ & 5 & $17 \%$ & 10 & $12 \%$ \\
\hline Indicadores contábeis e/ou covenants & 2 & $4 \%$ & 5 & $17 \%$ & 7 & $8 \%$ \\
\hline $\begin{array}{l}\text { Avaliação de Riscos com base nas DFs } \\
\text { (Classificação dos Arrendamentos) }\end{array}$ & 20 & $35 \%$ & 11 & $38 \%$ & 31 & $36 \%$ \\
\hline Efeitos tributários & 9 & $16 \%$ & 1 & $3 \%$ & 10 & $12 \%$ \\
\hline Gerenciamento de resultados/informações & 3 & $5 \%$ & - & $0 \%$ & 3 & $3 \%$ \\
\hline $\begin{array}{l}\text { Determinantes. Decisão entre arrendamento } \\
\text { ou compra/venda }\end{array}$ & 12 & $21 \%$ & 8 & $28 \%$ & 20 & $23 \%$ \\
\hline Decisões/Ações da Administração & 24 & $42 \%$ & 9 & $31 \%$ & 33 & $38 \%$ \\
\hline Total & 57 & $100 \%$ & 29 & $100 \%$ & 86 & $100 \%$ \\
\hline
\end{tabular}




\begin{tabular}{|c|c|c|c|c|c|c|}
\hline \multicolumn{7}{|c|}{ Painel B - Grupos temáticos por objeto de pesquisa analisado } \\
\hline Grupos/Subgrupos & Arrendatária & $\%$ & Arrendadora & $\%$ & Ambos & $\%$ \\
\hline $\begin{array}{l}\text { Efeitos/Impactos e(ou) Descrição/Críticas de } \\
\text { mudanças normativas }\end{array}$ & 7 & $12 \%$ & - & $0 \%$ & 2 & $15 \%$ \\
\hline Análise do processo normativo & 2 & $3 \%$ & - & $0 \%$ & 3 & $23 \%$ \\
\hline Comparação de normas & 2 & $3 \%$ & - & $0 \%$ & - & $0 \%$ \\
\hline Regras versus princípios & 5 & $8 \%$ & - & $0 \%$ & 1 & $8 \%$ \\
\hline Normatização do Arrendamento & 16 & $27 \%$ & - & $0 \%$ & 6 & $46 \%$ \\
\hline $\begin{array}{l}\text { Usuários, riscos e efeitos do (não) } \\
\text { reconhecimento do leasing }\end{array}$ & 13 & $22 \%$ & 1 & $8 \%$ & - & $0 \%$ \\
\hline Qualidade de disclosure/auditoria & 8 & $13 \%$ & 2 & $15 \%$ & - & $0 \%$ \\
\hline Indicadores contábeis e/ou covenants & 6 & $10 \%$ & 1 & $8 \%$ & - & $0 \%$ \\
\hline $\begin{array}{l}\text { Avaliação de Riscos com base nas DFs } \\
\text { (Classificação dos Arrendamentos) }\end{array}$ & 27 & $45 \%$ & 4 & $31 \%$ & - & $0 \%$ \\
\hline Efeitos tributários & 2 & $3 \%$ & 5 & $38 \%$ & 3 & $23 \%$ \\
\hline Gerenciamento de resultados/informações & 3 & $5 \%$ & - & $0 \%$ & - & $0 \%$ \\
\hline $\begin{array}{l}\text { Determinantes. Decisão entre arrendamento } \\
\text { ou compra/venda }\end{array}$ & 12 & $20 \%$ & 4 & $31 \%$ & 4 & $31 \%$ \\
\hline Decisões/Ações da Administração & 17 & $28 \%$ & 9 & $69 \%$ & 7 & $54 \%$ \\
\hline Total Geral & 60 & $100 \%$ & 13 & $100 \%$ & 13 & $100 \%$ \\
\hline
\end{tabular}

Fonte: elaboração própria

A maior parte das pesquisas internacionais está classificada no subgrupo "Usuários, riscos e efeitos do (não) reconhecimento do leasing", que procura avaliar os riscos nas DFs. Esse tema, em geral, prevê a capitalização das informações de leasing que estão off-balance (arrendamento operacional) e a consequente comparação dos saldos capitalizados versus não capitalizados para verificar possíveis comportamentos do mercado de capitais. Para responder a tal problema de pesquisa, faz-se necessária a aplicação de modelos analíticos. Em contrapartida, na pesquisa nacional, as categorias mais presentes têm abordagens mais qualitativas para a exploração do problema, como, por exemplo, o subgrupo "Qualidade de disclosure/auditoria", em que se observa uma maioria das pesquisas que analisam, de forma exploratória, se as empresas seguiram todas as exigências de disclosure exigidas na norma. Ainda, o subgrupo "Indicadores contábeis e/ou covenants" também foi explorado de forma a calcular indicadores, porém sem técnicas analíticas necessárias para a resposta ao problema de pesquisa. O mesmo ocorre no subgrupo "Determinantes". Decisão entre "arrendamento ou compra/venda". Entende-se essa diferença entre os cenários como sendo algo saudável, uma vez que se verificam diversas frentes de pesquisa pouco exploradas e que ainda podem ser examinadas.

Outro ponto é que, proporcionalmente, as pesquisas nacionais possuem uma divisão mais equitativa entre os grupos temáticos, enquanto as internacionais possuem maior peso para o grupo "Decisões/ Ações da Administração" e, depois, "Avaliação de Riscos com base nas DFs (Classificação dos Arrendamentos)". Essa diferença pode ser explicada pela maior existência de estudos de natureza tributária nos journals internacionais, reforçando o possível gap de produção, já que nacionalmente essa produção é pouco representativa. 
No painel B, percebe-se uma maior quantidade de estudos voltada para as arrendatárias (60 papers), enquanto são apenas 13 os artigos que analisam as arrendadoras unicamente. Verifica-se, portanto, a carência de estudos para arrendadoras, algo já argumentado (Bauman \& Francis, 2011). Isso não quer dizer que não haja caminho para tal. Por exemplo, não se verificou qualquer estudo com foco exclusivo para a arrendadora no grupo "Normatização do Arrendamento", algo curioso, tendo em vista que esse processo de normatização foi polêmico. Em todas as propostas normativas feitas pelo IASB e FASB, houve mudança relevantes para arrendadoras, sendo elas amplamente criticadas. Apesar de diversas propostas, a IFRS 16 não traz qualquer modificação para as arrendadoras, o que parece um tanto quanto incoerente, tendo em vista que antes argumentava-se a necessidade de simetria da contabilização entre arrendadoras e arrendatárias (Biondi et al., 2011). Esse fato pode gerar estudos que busquem entender o que levou as decisões dos normatizadores a se modificarem ao longo do processo, que podem ter focos em lobbying, grupos de interesse, teóricos e documentais.

Nas arrendatárias, porém, é previsível que a maior parte dos estudos esteja no grupo "Avaliação de Riscos com base nas DFs (Classificação dos Arrendamentos)", uma vez que a maior crítica para essas empresas deriva do fato da possível estruturação de operações e "maquiagem" do risco ao classificar as operações de arrendamento.

Percebe-se que ainda há interesse em verificar se as transações de leasing são realmente vantajosas frente à compra de bens, fato este que se torna de grande relevância atualmente, já que a norma não permite mais operações off-balance, ou seja, grande parte das empresas que se sentiam atraídas pelo arrendamento pela possibilidade contábil de não reconhecimento das dívidas em seus balanços agora não terão mais tal benefício. Portanto, fica a pergunta: será que a normatização contábil irá influenciar na decisão das empresas em arrendar ou comprar? Haverá efeito na forma de comercialização desses contratos?

Considerando que os estudos que têm como objeto arrendadoras e (ou) arrendatárias demonstraram diversos pontos de possibilidade de pesquisa, realizou-se, na Tabela 4, uma comparação desses objetos com as áreas de aplicação dos estudos.

Tabela 4

Relação da área de estudo com o enfoque do objeto analisado

\begin{tabular}{lccccc}
\hline \multicolumn{1}{c}{ Área do Estudo } & Arrendatária & Arrendadora & $\begin{array}{c}\text { Arrendatária / } \\
\text { Arrendadora }\end{array}$ & Total & $\%$ \\
\hline $\begin{array}{l}\text { Contabilidade Financeira/ } \\
\text { Teoria da Contabilidade }\end{array}$ & 39 & 4 & 5 & $\mathbf{4 8}$ & $\mathbf{5 6 \%}$ \\
\hline Tributária & 4 & 6 & 3 & $\mathbf{1 3}$ & $\mathbf{1 5 \%}$ \\
\hline Economia/Administração & 6 & 1 & - & $\mathbf{7}$ & $\mathbf{8 \%}$ \\
\hline Regulação & 3 & 1 & 3 & $\mathbf{7}$ & $\mathbf{8} \%$ \\
\hline Auditoria & 5 & - & - & $\mathbf{5}$ & $\mathbf{6 \%}$ \\
\hline Gerencial & 2 & 1 & - & $\mathbf{3}$ & $\mathbf{3} \%$ \\
\hline História & 1 & - & 2 & $\mathbf{3}$ & $\mathbf{3} \%$ \\
\hline Total Geral & $\mathbf{6 0}$ & $\mathbf{1 3}$ & $\mathbf{1 3}$ & $\mathbf{8 6}$ & $\mathbf{1 0 0 \%}$ \\
\hline$\%$ & $\mathbf{7 0 \%}$ & $\mathbf{1 5 \%}$ & $\mathbf{1 5 \%}$ & $\mathbf{1 0 0 \%}$ &
\end{tabular}

Fonte: elaboração própria

As arrendatárias possuem estudos em todas as áreas analisadas, com predominância para Contabilidade Financeira/Teoria da Contabilidade, já que esta é realmente a maior discussão conceitual do tema. Já as arrendadoras, apesar de representarem apenas $15 \%$ dos estudos da amostra, só não tiveram estudos na área de auditoria e história. Isso, além de demonstrar a carência de estudos nessas áreas, também leva à compreensão de que podem ser feitos estudos nas demais. Todos os grupos/subgrupos identificados nessa pesquisa, assim como as áreas de concentração da contabilidade, podem ter estudos voltados tanto para arrendadoras quanto para arrendatárias, sem exceção. 
Há, também, possibilidades de união das exatas categorias que não possuem qualquer estudo na amostra. Por exemplo, o subgrupo "regras versus princípios" pode ser analisado na área de auditoria e controle interno: como as empresas arrendadoras selecionam, e as auditoras validam, a classificação do arrendamento (financeiro ou operacional) de forma a garantir a comparabilidade dessas operações? Há que se considerar que a norma internacional possui princípios norteadores e a norma norte-americana possui regras que determinam tal classificação. Os controles internos podem garantir a correta aplicação desses princípios ou regras? Essa questão, por exemplo, ainda é relevante, já que a norma para arrendadoras continua com a classificação entre financeiro e operacional.

Com base na diversidade apresentada, a última análise refere-se a possível especialização de autores na produção. Essa análise pode ser realizada pela quantidade de produções que cada autor possui sobre o tema. Assim, espera-se que autores com mais produção sobre o tema tenham real linha de pesquisa voltada para tal.

Como pode ser observado na Tabela 5, painel A, foram identificados 228 autorias (aqui conta-se a totalização de autores, sem levar em consideração se ele apareceu mais de uma vez) nos 86 papers: uma média de 2,65 autores por paper. Ao se analisar o painel B, tem-se um total de 212 autores diferentes (13 autores produziram mais de 1 artigo sobre o tema e 199 produziram 1 paper).

Tabela 5

\section{Dados de autorias e autores}

\begin{tabular}{|c|c|c|c|c|c|c|c|c|}
\hline \multicolumn{9}{|l|}{ Painel A - Média de autorias } \\
\hline Origem & Amostra & Autorias & \multicolumn{6}{|c|}{ Média de autores por paper } \\
\hline Internacional & 57 & 140 & \multicolumn{6}{|c|}{2,46} \\
\hline Nacional & 29 & 88 & \multicolumn{6}{|c|}{3,03} \\
\hline Total/Média & 86 & 228 & \multicolumn{6}{|c|}{2,65} \\
\hline \multicolumn{9}{|l|}{ Painel B - Autores com mais de 1 produção } \\
\hline Autores & $\begin{array}{l}\text { Cont } \\
\text { Fin }\end{array}$ & Trib & $\begin{array}{l}\text { Eco / } \\
\text { Adm }\end{array}$ & Reg & Aud & Ger & Hist & Total \\
\hline Jorge Katsumi Niyama & 4 & & & 1 & & & & 5 \\
\hline Autores nacionais (3) com 2 publicações cada & 2 & & 2 & & & 2 & & 6 \\
\hline Autores internacionais (9) com 2 publicações cada & 15 & & & 1 & 2 & & & 18 \\
\hline Outros (199) autores com 1 produção & 117 & 20 & 19 & 18 & 13 & 6 & 6 & 199 \\
\hline Total & 138 & 20 & 21 & 20 & 15 & 8 & 6 & 228 \\
\hline
\end{tabular}

Fonte: elaboração própria

Dos autores com mais de uma produção, quatro são nacionais e, destes, apenas um (Jorge Katsumi Niyama) com mais de dois artigos. Isso demonstra que é uma área de baixa especialização. Ao analisar o autor que mais publicou, verifica-se que sua dedicação ao tema ocorre desde sua dissertação de mestrado, que verifica questões contábeis das arrendadoras no Brasil, em 1982. O autor possui grupos de pesquisa sobre normatização contábil, o que justifica sua produção nas áreas de Contabilidade Financeira e Regulação. Ao total, foram cinco artigos produzidos nesse período, o que representa $17 \%$ dos nacionais (5/29). 


\section{Revisão Narrativa da Literatura}

\subsection{Normatização do arrendamento}

Há quatro subgrupos no grupo "Normatização do Arrendamento". A maioria dos estudos possui uma relação natural com a normatização, uma vez que se utilizam de normas para avaliação de algum critério contábil, porém não são todos os estudos que podem ser encaixados nesse grupo. Compõem o grupo aqueles estudos que têm como objetivo análises de componentes normativos, como: premissas de escolhas contábeis, o processo em si, ou críticas a mudanças das normas.

No primeiro subgrupo "Efeitos/Impactos e (ou) Descrição/Críticas de mudanças normativas", podem-se encontrar estudos que analisam pontos das propostas normativas feitas sobre o assunto, tendo como principal tópico a capitalização do arrendamento (Biondi et al., 2011; Lipe, 2001; Monson, 2001; Ryan, Herz, Iannaconi, Maines, Palepu, Schipper \& Vicente, 2001; Spencer \& Webb, 2015). Entre esses estudos, há um consenso, com relação à necessidade de mudanças nas normas internacionais, em defesa da necessidade de um modelo único de capitalização para as arrendatárias.

Para subsidiar os argumentos, algumas críticas principais são feitas às propostas normativas, como: bright-linetests; arbitrariedade; estruturação das transações; baixa comparabilidade e alta complexidade; comportamento oportunista de gestores; apresentação off-balance e não reconhecimento de passivos; falta de simetria e brechas contábeis (Biondi et al., 2011; Franzen, Cornaggia \& Simin, 2009; Jamal \& Tan, 2010; Lipe, 2001).

Apesar de parecer haver um consenso acadêmico sobre o fim da classificação do arrendamento, gerando a capitalização de todos os contratos pelas arrendatárias e suprindo as definições de ativo e passivo da estrutura conceitual, ainda não há consenso, nesses estudos, sobre a contabilização de opções contratuais, como: valor residual garantido e aluguéis contingentes, sendo esses temas férteis para a pesquisa conceitual, que podem contribuir ao debate acadêmico e profissional.

Apesar disso, na prática essa realidade se torna diferente. Comiran e Graham (2016), já classificados no subgrupo "Análise do processo normativo", demonstram que, em análise da participação de usuários no processo normativo da IFRS 16, mais de $25 \%$ dos respondentes são a favor da capitalização do arrendamento, porém $75 \%$ são contrários a mudanças nas normas. Os achados são contraditórios e não se sabe, ao certo, qual o posicionamento dos usuários frente às mudanças. Maiores pesquisas podem ser realizadas para tentar compreender esse comportamento paradoxal e possíveis vieses que são vistos como problemáticos por parte dos usuários para mudanças normativas.

Os outros estudos desse subgrupo seguem a mesma linha de pesquisa, voltados para questões sobre lobbying e participação de usuários no processo normativo. Há pesquisas que analisam o Discussion $\mathrm{Pa}$ per (Carmo, Ribeiro \& Carvalho, 2014), Exposure Draft (Matos, 2013) ou o processo de forma mais geral (Comiran \& Graham, 2016; Larson \& Herz, 2011). Em todas, observa-se que a participação dos usuários pode influenciar na decisão de conceitos por parte dos normatizadores.

O subgrupo "Comparação de normas" teve apenas classificações de estudos nacionais. A comparação, nesse caso, foi entre normas fiscais e as normas contábeis. Por meio de pesquisas documentais, foram levantados pontos em que as normas eram contrastantes.

Por fim, os estudos de "Regras versus princípios" formam um subgrupo em que o leasing figura, em sua maioria, como objeto de pesquisa e não como tema em si. Isso ocorre porque a norma de arrendamento é uma das mais conhecidas para a comparação da dualidade regras $x$ princípios, já que a norte-americana possui critérios baseados em regras (bright-linetests) para a classificação dos arrendamentos e a internacional é baseada em princípios, sendo esse um ambiente experimental interessante para pesquisas (Cohen, Krishnamoorthy, Peytcheva \& Wright, 2013). Esse tema, portanto, é explorado tanto na Contabilidade Financeira quanto na Auditoria, assim como com métodos de experimento, teóricos e analíticos. 
Entre as pesquisas, há evidências de utilização da dualidade regras versus princípios de forma oportunista por parte da administração das empresas (Jamal \& Tan, 2010), sendo que esta modifica o comportamento dos auditores (Cohen et al., 2013), assim como tendências diferenciadas de classificação dos arrendamentos (semelhantes) em normas com perspectivas diferentes de princípios versus regras (Collins, Pasewark \& Riley, 2012). Esses achados, porém, não são consensuais, tendo em vista que Henderson e O’Brien (2017) não encontraram diferenças na classificação dos arrendamentos.

Não foram encontrados estudos sobre custos regulatórios, porém esses estudos podem ser realizados, já que entre as críticas a essa norma está o fato de seu custo-benefício não ser compensatório, principalmente em decorrência da necessidade de revisão de todos os contratos e da aquisição de sistemas de controles específicos para arrendamentos. Do outro lado, o possível benefício pode não ser tão evidente, já que o mercado tende a ajustar as informações off-balance e a mudança normativa pode não ter efeito sobre a avaliação do mercado (Bratten, Choudhary \& Schipper, 2013).

Portanto, por mais que existam estudos em diversos métodos, áreas e subgrupos sobre normatização e arrendamento, esse ainda é um grupo fértil para pesquisas, principalmente se for considerado que o processo terminou recentemente e estudos podem analisar todo o processo. Observa-se, também, uma condição relevante o fato de o FASB e do IASB terem lançado normas finais diferentes, com características de reconhecimento e mensuração também distintas, como a forma de reconhecimento das despesas por parte das arrendatárias. Esse fato pode ser alvo tanto de pesquisas comparativas como de possíveis impactos dessas diferenças e até mesmo de questões relacionadas com lobbying e grupos de interesses.

\subsection{Avaliação de riscos com base nas DFs (classificação dos arrendamentos)}

A maioria das pesquisas que têm o leasing como tema ou objeto de estudo possui alguma relação, direta ou indireta, com a possibilidade de classificação do arrendamento em operacional ou financeiro (Spencer \& Webb, 2015). Nesse grupo, porém, são classificados os estudos que relacionam a classificação do arrendamento com informações contábeis e participantes do mercado. Seus objetivos, em geral, buscam compreender os efeitos e riscos derivados dos modelos de classificação.

O primeiro subgrupo, "Usuários, risco e efeitos do (não) reconhecimento do leasing", é formado por uma maioria de estudos que procura verificar como os participantes do mercado entendem e reagem às informações apresentadas nas situações de arrendamento operacional (off-balance) e como isso influencia a tomada de decisão, ou seja, como os participantes do mercado avaliam os riscos das empresas tomando como base a classificação dos arrendamentos (Kusano, 2018).

Essas pesquisas são aplicadas, principalmente, nas arrendatárias e, por sua natureza, são de maioria analítica, porém podem ser realizadas com diversos métodos, como surveys, experimentos e modelagem, entre outros. Como principal base metodológica, aparecem estudos que propõem métodos de capitalização do arrendamento, como Beattie, Goodacre e Thomson (1998), Ely (1995) e Imhoff Jr. et al. (1991). Até o momento, esse método se torna necessário para que possa ser feita uma quantificação dos efeitos de possíveis capitalizações.

A aplicação dessa categoria também já foi realizada em diferentes cenários, como Estados Unidos (Bratten et al., 2013), (Bratten et al., 2013, Austrália (Xu, Davidson \& Cheong, 2017), Brasil (Martins, Machado \& Machado, 2013), Reino Unido (Beattie, Goodacre \& Thomson, 2000) e Japão (Kusano, 2018), sendo os achados ainda não consensuais. Isso pode abrir margem para interpretações, como falha na estimação de modelos ou reais diferenças entre países, porém um fato é real: ainda há campo de estudo sobre esse tema, principalmente se for considerada que a maior crítica à normatização atual é a possível não relevância contábil das informações off-balance. 
Outro ponto que pode ser alvo de pesquisas com o objetivo de avançar na produção da área é a criação de novos modelos de capitalização mais modernos e convergentes às propostas recentes. Esses modelos poderão ser contrastados, a partir de 2019, com a efetiva aplicação por parte das empresas, contribuindo para as áreas de Contabilidade Financeira e Auditoria. Por ser uma proposta nova, frameworks de avaliações dessas informações também podem contribuir para a avaliação de riscos por parte do mercado

Ainda com relação à avaliação do mercado sobre as informações de arrendamento, alguns autores mostram, principalmente no cenário americano, que usuários sofisticados conseguem extrair a informação off-balance e levar tais pontos em suas considerações na avaliação de risco das empresas. Sendo assim, não seria necessária modificação na normatização, uma vez que capitalizar, ou não, as informações de arrendamento não modificaria a opinião dos investidores mais sofisticados (Bratten et al., 2013). Entretanto, propostas de pesquisa podem ser realizadas ao contrastar esse argumento com a alegada função social da Contabilidade. Deve a Contabilidade se preocupar com informações que já são ajustadas pelos usuários? Há diferença no ganho (social ou econômico) entre os usuários que possuem recursos para realizar tais ajustes?

Os estudos do subgrupo "Qualidade de disclosure/auditoria” também se utilizam da diferença contábil decorrente dos modelos de classificação, porém com contribuição ao debate sobre disclosure e riscos, tanto com o viés financeiro quanto de auditoria. A principal linha de pesquisa busca verificar se as informações são vistas como completas, ou seja, se as demonstrações financeiras proporcionam todos os dados necessários para correto julgamento por parte dos usuários. Essas pesquisas tendem a avaliar as notas explicativas de arrendatárias (Zechman, 2010), arrendadoras (Bauman \& Francis, 2011) e de pontos específicos da norma, como as opções de renovação (Hales, Venkataraman \& Wilks, 2012).

Nesses estudos, os autores encontraram, por meio de técnicas de levantamento exploratório, a não completude das informações solicitadas nas normas. Isso leva a um debate sobre regulação que pode ser contrastado com o do subgrupo anterior. Questiona-se, se as informações não são completas, como o mercado e os investidores podem aferir corretamente seus efeitos? A regulação está solicitando informações além do necessário para a avaliação do mercado? Ou será que as informações não são consideradas materialmente relevantes, pelos preparadores e auditores, a ponto de serem evidenciadas em sua completude?

O último subgrupo dessa seção é o de "Indicadores contábeis e/ou covenants", que também apresenta relação direta com o comportamento dos usuários na avaliação de risco das entidades, porém toma-se como premissa que as obrigações não reconhecidas são relevantes no cálculo de indicadores contábeis e, por consequência, em taxas de juros e covenants.

Com relação às covenants, a única pesquisa da amostra que avalia tal ponto chega a conclusão de que os credores já levam em consideração as informações off-balance na estipulação desses contratos, ou seja, mesmo com as mudanças, essas informações não levariam à quebra de contratos (Paik, van der Laan Smith, Lee, \& Yoon, 2015). Apesar disso, essa pesquisa é realizada tomando como base o cenário sofisticado norte-americano. Para uma correta previsão desse fenômeno, há espaço para esse estudo em demais cenários, até mesmo menos sofisticados, contribuindo ao debate sobre a convergência e seus efeitos.

Por fim, os estudos sobre comparação de indicadores tendem a utilizar setores específicos em suas análises, isso porque muitas vezes a subjetividade desses indicadores varia entre setores. Portanto, exemplos sobre avaliação de empresas podem ser vistos em análises do setor aéreo, de transportes e instituições financeiras. Entretanto, não foram encontrados estudos que focam na análise de indicadores financeiros com foco em setores que também possuem impacto relevante de arrendamento operacional, como serviços, hotelaria e varejo. 


\subsection{Decisões/Ações da Administração}

No último grupo ("Decisões/Ações da Administração") foram classificados os estudos que têm como premissa análises que impactam de forma mais direta os efeitos internos às entidades, principalmente aqueles que dependem de ações da própria administração.

O primeiro subgrupo - "Efeitos tributários" - apresenta maior quantidade de estudos técnicos, como já discutido. A única pesquisa que não possui essa origem é a de Roza, Alberton e Limongi (2008), que procura verificar pontos de arrecadação de um imposto local em decorrência das operações de arrendamento. Essa ausência de estudos acadêmicos sobre efeitos tributários pode ser justificada pela dificuldade na obtenção de dados; porém essa dificuldade também abre frente para estudos de outras naturezas, como estudos de caso ou de cunho mais exploratório.

Sobre "Gerenciamento de resultados/informações", cabe ressaltar que são estudos que visam a verificação do gerenciamento de forma interna à entidade, ou seja, momentos em que a entidade opta por determinar os níveis ótimos de informações a serem dadas ao mercado. As pesquisas são mais exploratórias e normalmente voltadas para estudos de caso individuais. A dificuldade na obtenção dos dados faz com que essas pesquisas representem um pequeno efeito sobre o que é pesquisado sobre arrendamento, mas de grande valia para a área. A lógica principal é analisar como a manipulação de informações é feita para limitar potenciais impactos de uma regulação (Bátiz-Lazo \& Billings, 2012).

Por fim, o subgrupo "Determinantes. Decisão entre arrendamento ou compra/venda" já foi alvo de uma revisão de literatura no cenário internacional (Morais, 2013). Nessa categoria há estudos aplicados em diferentes cenários, como tabaco, manufatura, terras e financeiro, entre outros, com foco maior para decisões da arrendatária. Não há achados generalizados. Entende-se, até então, que a decisão para a realização de arrendamento, assim como seus determinantes, varia de acordo com a empresa, cenário institucional, vantagens tributárias e diversos outros fatores, o que dificulta estudos comparativos com amostras de grande vulto.

Com base na análise desse grupo temático, uma pergunta que permeia muitos dos estudos tangencia o debate sobre a proatividade da Contabilidade. Nesse caso, deveria a contabilidade ser proativa em modificações que podem influenciar nos modelos de negociação dos contratos? Se a Contabilidade se antecipar na normatização, ela poderia influenciar o modelo de negociação, seria esse seu objetivo? Os estudos não respondem tal pergunta, porém ela faz uma ponte entre diversas áreas da Contabilidade, representando um interessante tema de investigação.

\section{Considerações Finais}

Objetivou-se, na presente pesquisa, realizar uma revisão de literatura - baseada nos diferentes pressupostos metodológicos de Paré et al. (2015) - com o objetivo de identificar e caracterizar a produção científica sobre arrendamento mercantil na área de Contabilidade no período de 2000 a 2018. Na consecução dessa análise, uma amostra de 86 artigos foi selecionada e classificada conforme sua aplicação temática. Foram criados três grupos temáticos, subdivididos em dez subgrupos que foram balizadores para a revisão narrativa da literatura.

Como diversas pesquisas foram analisadas nesse paper, ressalta-se que todas as leituras realizadas não possuíram o objetivo de criticar ou qualificar a pesquisa internacional versus nacional como concorrentes, mas, sim, mostrar diversas frentes de pesquisa que podem ser ainda exploradas por pesquisadores brasileiros. Por fim, ressalta-se que no próprio corpo do paper foram levantados pontos e possibilidades de perguntas de pesquisas futuras, já que essas possibilidades de pesquisa são oriundas das lacunas encontradas em cada categoria. 
A sumarização de pesquisas demonstra que, em sua maioria, os estudos possuem um foco para a análise de critérios contábeis do leasing relacionados com a classificação entrefinanceiro e operacional. O fato de haver condições contábeis diferentes para cada classificação leva a uma produção que envolve diversas frentes de análise, como disclosure, indicadores contábeis, qualidade da informação, análises de riscos, determinantes e decisões de comprar ou arrendar.

Um dos marcos esperados para esses estudos está na emissão da nova norma internacional sobre o tema (IFRS 16), que, além de extinguir essa classificação, exige o mesmo tratamento contábil para todas as arrendatárias, qual seja o de reconhecer todas as operações de arrendamento como ativo e passivo. Assim, possíveis vantagens de alguma categoria foram extintas e as empresas terão que se reorganizar para avaliar os impactos aos riscos e ao próprio negócio, porém não somente a Regulação e a Contabilidade Financeira que são exploradas sobre o assunto. Há estudos que também analisam pontos de interesse para a auditoria, efeitos tributários e gerencial, o que demonstra a contínua relevância do tema e sua importancia para diferentes frentes de pesquisa.

Um destaque ocorre para a carência de estudos com foco nas arrendadoras, sendo que o grupo "Normatização do Arrendamento" não apresentou qualquer estudo com essas entidades como foco principal. Essa frente de pesquisa pode ser promissora, principalmente se for considerado os diversos possíveis mar$\cos$ da normatização das arrendadoras. Esse processo foi marcado por mudanças nas propostas normativas do FASB e do IASB, inclusive sendo alvo de desentendimentos entre os órgãos e sendo considerado como um ponto polêmico da normatização. Nesse sentido, diversas frentes podem ser analisadas, desde discussões teóricas sobre as vantagens/desvantagens, custo/benefício até visões empíricas sobre participações dos usuários, lobbying, grupos de interesses e impactos das diferentes propostas, entre outros.

Não há definição clara de diferenças nas pesquisas nacionais e internacionais no que concerne aos resultados encontrados, porém percebe-se que o cenário institucional é de grande efeito nas análises, já que cada ambiente possui vantagens diferentes para as operações de leasing. Esse fato faz com que seja mais difícil a implementação de pesquisas empíricas em ambientes internacionais (comparação entre diferentes mercados), porém não limita a condição de pesquisas, o que pode acabar por contribuir para a identificação de mais pontos de pesquisa internacionais.

As diferenças e lacunas entre grupos/subgrupos na classificação de pesquisas nacionais e internacionais não devem ser vistas como contradições, mas, sim, como possibilidades de extensão da literatura. Entre os exemplos, estão os estudos de natureza tributária, que são mais presentes no ambiente americano, mas podem ser exploradas nos mais diversos cenários. Corroborando o argumento anterior, essa é uma área de estudos que pode ser explorada nos diversos cenários institucionais, de forma que pode contribuir, inclusive, para às análises sobre convergência, uma vez que os efeitos tributários influenciam a implantação de diversas normas contábeis.

Com relação à normatização, um dos pontos de preocupação sobre o tema é oriundo exatamente dessa mudança. Como grande parte das pesquisas sobre leasing se baseavam na dicotomia contábil gerada pelos diferentes modelos de contabilização, será que agora que não existirá mais tal fato as pesquisas sobre o tema se tornarão irrelevantes? Pode-se dizer que, a princípio, não. Após a implementação da IFRS 16 , espera-se que as pesquisas possam realmente analisar se as previsões dos estudos anteriores ocorreram de fato, ou seja, se os problemas levantados pela literatura realmente foram extintos após a regulação contábil. Aqui entra outro debate, sendo ele relacionado com a função da Contabilidade em si. Nesse sentido, as mudanças contábeis podem influenciar a forma como os contratos de arrendamento são negociados, ou seja, a Contabilidade teria um efeito proativo na negociação desse tipo de operação. Seria esse o objetivo da área? Ou a área deve se restringir a tentar ser reativa e espelhar as necessidades do mercado? Será que a normatização contábil irá influenciar a decisão das empresas em arrendar ou comprar? Haverá efeito na forma de comercialização desses contratos? 
Além destas perguntas, ressalta-se a necessidade de estudos sobre pontos de análise em que ainda não há consensos, como a contabilização de opções contratuais, valor residual garantido e aluguéis contingentes. Outro ponto de interesse acadêmico e prático, porém não explorado com aplicação na norma de leasing, refere-se aos custos regulatórios que essa norma traz consigo. Muito se fala em custo/benefício da informação, porém são restritas as pesquisas empíricas que analisam tal situação. Ainda, perguntas foram identificadas com relação à função social da Contabilidade. Como o arrendamento é um tema de relevância internacional e interesse dos mais diversos constituintes, não há consenso sobre a quantidade de informações a serem dadas e se o mercado realmente precisa dessas informações para avaliar o risco das empresas. Nesse sentido, a Contabilidade privilegia, ao decidir as informações a serem dadas, os usuários mais qualificados? Se as informações não são completas, como o mercado e os investidores podem aferir corretamente seus efeitos? A regulação está solicitando informações além do necessário para a avaliação do mercado? Ou será que as informações não são consideradas relevantes o suficiente, pelos preparadores e auditores, a ponto de serem evidenciadas em sua completude?

Por fim, os critérios de qualidade da produção tangenciaram a análise, porém não foram explorados no paper. Entende-se que a seleção dos journals mais relevantes da área já é um pré-julgamento sobre a qualidade. Porém algo que foi notado é que, ao se analisarem os artigos nacionais e internacionais, aparentou-se haver uma diferença nos embasamentos teóricos que as justificam, ou seja, não parecem ter sido utilizadas as mesmas teorias ou estudos base. Muitos se baseiam na natureza de classificação (operacional e financeiro) para suas análises, portanto, a princípio não haveria motivo para grande diferença na utilização de referências, sendo esta uma das contradições encontradas e que podem ser exploradas em pesquisas futuras.

\section{Referências}

Ang, J. \& Peterson, P. P. (1984). The Leasing Puzzle. The Journal of Finance, 39(4), p.1055. https://doi. org/10.2307/2327612

Barone, E., Birt, J. \& Moya, S. (2014). Lease Accounting: A Review of Recent Literature. Accounting in Europe, 11(1), pp. 35-54. https://doi.org/10.1080/17449480.2014.903630

Bátiz-Lazo, B. \& Billings, M. (2012). Accounting Regulation and Management Discretion-A Case Note. Abacus, 48(3), pp. 414-437. https://doi.org/10.1111/j.1467-6281.2012.00370.x

Bauman, M. P. \& Francis, R. N. (2011). Issues in Lessor Accounting: The Forgotten Half of Lease Accounting. Accounting Horizons, 25(2), pp. 247-266. https://doi.org/10.2308/acch-10021

Beattie, V., Edwards, K. \& Goodacre, A. (1998). The impact of constructive operating lease capitalisation on key accounting ratios. Accounting and Business Research, 28(4), pp. 233-254. https://doi.org/10 $.1080 / 00014788.1998 .9728913$

Beattie, V., Goodacre, A. \& Thomson, S. (2000). Recognition versus Disclosure: An Investigation of the Impact on Equity Risk Using UK Operating Lease Disclosures. Journal of Business Finance \& Accounting, 27(9\&10), pp. 1185-1224. https://doi.org/10.1111/1468-5957.00352

Biondi, Y., Bloomfield, R. J., Glover, J. C., Jamal, K., Ohlson, J. A., Penman, S. H., ... Jeffrey Wilks, T. (2011). A perspective on the joint IASB/FASB exposure draft on accounting for leases. Accounting Horizons, 25(4), pp. 861-871. https://doi.org/10.2308/acch-50048

Bowman, R. (1980). The Debt Equivalence Of Leases: An Empirical Investigation. The Accounting Review, 55(2), pp. 237-253. Retrieved from http://www.jstor.org/stable/246342

Bratten, B., Choudhary, P. \& Schipper, K. (2013). Evidence that Market Participants Assess Recognized and Disclosed Items Similarly when Reliability is Not an Issue. The Accounting Review, 88(4), pp. 1179-1210. https://doi.org/10.2308/accr-50421 
Carmo, C. H. S. do, Ribeiro, A. M. \& Carvalho, L. N. G. de. (2014). Influência dos Grupos de Interesse no Processo de Normatização Contábil Internacional: o Caso do Discussion Paper sobre Leasing. Revista Contabilidade Vista \& Revista, 25(2), pp. 98-118.

Cohen, J. R., Krishnamoorthy, G., Peytcheva, M. \& Wright, A. M. (2013). How Does the Strength of the Financial Regulatory Regime Influence Auditors' Judgments to Constrain Aggressive Reporting in a Principles-Based Versus Rules-Based Accounting Environment? Accounting Horizons, 27(3), pp. 579-601. https://doi.org/10.2308/acch-50502

Collins, D. L., Pasewark, W. R. \& Riley, M. E. (2012). Financial Reporting Outcomes under Rules-Based and Principles-Based Accounting Standards. Accounting Horizons, 26(4), pp. 681-705. https://doi. org/10.2308/acch-50266

Comiran, F. \& Graham, C. M. (2016). Comment letter activity: A response to proposed changes in lease accounting. Research in Accounting Regulation, 28(2), pp. 109-117. https://doi.org/10.1016/j.racreg.2016.09.010

Ely, K. M. (1995). Operating Lease Accounting and the Market's Assessment of Equity Risk. Journal of Accounting Research, 33(2), p. 397. https://doi.org/10.2307/2491495

Franzen, L., Cornaggia, K. R. \& Simin, T. T. (2009). Capital Structure and the Changing Role of Off-Balance-Sheet Lease Financing. SSRN Electronic Journal, (April 2008). https://doi.org/10.2139/ ssrn. 1452971

Hales, J. W., Venkataraman, S. \& Wilks, T. J. (2012). Accounting for Lease Renewal Options: The Informational Effects of Unit of Account Choices. The Accounting Review, 87(1), pp. 173-197. https:// doi.org/10.2308/accr-10165

Henderson, D. \& O'Brien, P. C. (2017). The standard-setters' toolkit: can principles prevail over bright lines? Review of Accounting Studies, 22(2), pp. 644-676. https://doi.org/10.1007/s11142-017-9392-4

Imhoff, E. A. \& Thomas, J. K. (1988). Economic consequences of accounting standards. Journal of Accounting and Economics, 10(4), pp. 277-310. https://doi.org/10.1016/0165-4101(88)90006-7

Imhoff Jr., E. a, Lipe, R. C. \& Wright, D. W. (1991). Operating Leases: Impact of Constructive Capitalization. Accounting Horizons, 5(1), pp. 51-63.

Jamal, K. \& Tan, H. T. (2010). Joint effects of principles-based versus rules-based standards and auditor type in constraining financial managers' aggressive reporting. Accounting Review, 85(4), pp. 13251346. https://doi.org/10.2308/accr.2010.85.4.1325

Kusano, M. (2018). Effect of capitalizing operating leases on credit ratings: Evidence from Japan. Journal of International Accounting, Auditing and Taxation, 30(March), pp. 45-56. https://doi.org/10.1016/j. intaccaudtax.2017.12.008

Largay III, J. A. (2001). Commentaries on Acccounting for Leases. Accounting Horizons, 15(3), pp. 273273. https://doi.org/10.2308/acch.2001.15.3.273

Larson, R. K. \& Herz, P. J. (2011). The academic community's participation in global accounting standard-setting. Research in Accounting Regulation, 23(1), pp. 34-45. https://doi.org/10.1016/j.racreg.2011.03.006

Lipe, R. C. (2001). Lease Accounting Research and the G4+1 Proposal. Accounting Horizons, 15(3), pp. 299-310. https://doi.org/10.2308/acch.2001.15.3.299

Martins, V. G., Machado, M. A. V. \& Machado, M. R. (2013). Value Relevance das informações de Leasing Operacional: um estudo em empresas brasileiras. Enfoque: Reflexão Contábil, 32(2), pp. 83-99. https://doi.org/10.4025/enfoque.v32i2.19762 
Massaro, M., Dumay, J. \& Guthrie, J. (2016). On the shoulders of giants: undertaking a structured literature review in accounting. Accounting, Auditing \& Accountability Journal, 29(5), pp. 767-801. https://doi.org/10.1108/AAAJ-01-2015-1939

Matherly, M. \& Shortridge, R. T. (2009). A pragmatic model to estimate journal quality in accounting. Journal of Accounting Education, 27(1), pp. 14-29. https://doi.org/10.1016/j.jaccedu.2009.07.001

Matos, E. B. S. de. (2013). Critérios de Reconhecimento, Mensuração e Apresentação das operações de leasing segundo a minuta de pronunciamento (ED/2010/9) do IASB: análise da opinião dos usuários da informação contábil. Dissertação de Mestrado, Programa Multiinstitucional e Inter-Regional de Pós-Graduação em Ciências Contábeis (UnB/UFPB/UFRN), Brasília, DF, Brasil.

Matos, E. B. S. de, Araújo, L. V. L. de, Guerra, M. \& Murcia, F. D. (2017). Estudos Internacionais Sobre Valor Justo (2000-2016): Temáticas, Métodos e Sugestões de Pesquisas Futuras. Revista de Educação e Pesquisa Em Contabilidade (REPeC), 11(3), pp. 276-295. https://doi.org/10.17524/repec.v11i3.1559

Matos, N. B. \& Niyama, J. K. (2018). IFRS 16 - Leases: Challenges, Perspectives and Implications in the Light of Substance Over Form. Revista de Educação e Pesquisa Em Contabilidade (REPeC), 12(3), pp. 323-340. https://doi.org/10.17524/repec.v12i3.1858

McGregor, W. (1996). Accounting for Leases: A New Approach. Financial Accounting Series No.. 163-A. Norwalk, CT: Financial Accounting Foundation.

Monson, D. W. (2001). The conceptual framework and accounting for leases. Accounting Horizons, 15(3), pp. 275-287. https://doi.org/10.2308/acch.2001.15.3.275

Morais, A. I. (2013). Why companies choose to lease instead of buy? Insights from academic literature. Academia, 26(5), pp. 432-446. https://doi.org/10.1108/ARLA-07-2013-0091

Nailor, H. \& Lennard, A. (2000). LEASES: Implementation of a New Approach. Financial Accounting Series $N^{o} . .206-A$. Norwalk, CT: Financial Accounting Foundation.

Nascimento, A. R. do, Santos, A. dos, Salotti, B. M. \& Murcia, F. D.-R. (2009). Disclosure social e ambiental: Análise das pesquisas científicas veiculadas em periódicos de língua inglesa. Contabilidade Vista \& Revista, 20(1), pp. 15-40. Retrieved from http://web.face.ufmg.br/face/revista/index.php/ contabilidadevistaerevista/article/view/572

Paik, D. G. H., van der Laan Smith, J. A., Lee, B. B. \& Yoon, S. W. (2015). The Relation between Accounting Information in Debt Covenants and Operating Leases. Accounting Horizons, 29(4), pp. 969-996. https://doi.org/10.2308/acch-51214

Paré, G., Trudel, M. C., Jaana, M. \& Kitsiou, S. (2015). Synthesizing information systems knowledge: A typology of literature reviews. Information and Management, 52(2), pp. 183-199. https://doi. org/10.1016/j.im.2014.08.008

Reither, C. L. (1998). What are the Best and the Worst Accounting Standards? Accounting Horizons, 12(3), pp. 283-292.

Roza, M. M. C., Alberton, L. \& Limongi, B. (2008). A Gestão Tributária do Leasing Como Fonte de Receita Municipal. Revista de Contabilidade Do Mestrado Em Ciências Contábeis Da UERJ, 13(3), pp.1-10. Retrieved from http://www.atena.org.br/revista/ojs-2.2.3-09/index.php/uerj/article/viewFile/26/26

Ryan, S. G., Herz, R. H., Iannaconi, T. E., Maines, L. A., Palepu, K. G., Schipper, K. \& Vincent, L. (2001). Evaluation of the Lease Accounting Proposed in G4+1 Special Report. Accounting Horizons, 15(3), pp. 289-298. https://doi.org/10.2308/acch.2001.15.3.289

Smith, M. (2003). Research Methods in Accounting. Thousand Oaks, California: SAGE Publications.

Spencer, A. W. \& Webb, T. Z. (2015). Leases: A review of contemporary academic literature relating to lessees. Accounting Horizons, 29(4), pp. 997-1023. https://doi.org/10.2308/acch-51239 
Wolk, H. I., Dodd, J. L. \& Rozycki, J. J. (2008). Accounting Theory: Conceptual Issues in a Political and Economic Environment (7th ed.). Thousand Oaks, CA: Sage Publications, Inc.

Xu, W., Davidson, R. A. \& Cheong, C. S. (2017). Converting financial statements: operating to capitalised leases. Pacific Accounting Review, 29(1), pp. 34-54. https://doi.org/10.1108/PAR-01-2016-0003

Zechman, S. L. C. (2010). The Relation Between Voluntary Disclosure and Financial Reporting: Evidence from Synthetic Leases. Journal of Accounting Research, 48(3), pp. 725-765. https://doi.org/10.1111/ j.1475-679X.2010.00376.x 